\title{
Drawing Matter
}

This issue of arq proudly introduces our new collaboration with the remarkable Drawing Matter archive. The archive's website records its location in a farmyard in a small valley in the West of England, noting laconically how 'besides cows, sheep, tractors and a significant group of buildings by contemporary architects, it houses a collection of many thousand architectural drawings and models, ranging from the 16th to the 21st century'. ${ }^{1}$ Assembled over twenty-five years, the collection is striking in its range and depth. A glance at the catalogue includes - just under ' $\mathrm{L}$ ' - drawings from Henri Labrouste, John Lautner, Le Corbusier, Raymond Loewy, and Edwin Lutyens, among numerous others. Future issues of arq will include individual drawings specially selected from the archive for our pages.

To launch our collaboration, and in continued celebration of arq's recent twenty-first anniversary, this issue opens with an insightful collection of twenty-one pairs of plan drawings (pp. 8-40, see also our last issue, 21.4). Stan Allen, Niall Hobhouse, and Helen Mallinson chose the images in an intense one-day session. As Allen reflects: 'The architectural plan is a paradoxical sort of object, an instrument that should be rendered obsolete by the act of construction [which] nonetheless remains the most intensive and compact description of an architectural idea.' Ranging across the work of Louis Kahn and Superstudio, Charles Barry and James Stirling, John Soane and Karel Lodr, the selection reflects on 'plan' as both verb and noun: as a tool directed towards an outcome, awaiting construction and inhabitation; and also as the retrospective reconstruction of existing architectures towards education and knowledge. Allen goes on to argue, 'the conceptual power of the plan as a working instrument is [...] its capacity to function simultaneously as an analytical and projective device, poised between past histories and future possibilities'. In a similar spirit, we at arq look forward to the future possibilities of including past histories from Drawing Matter's collection in the pages of the journal. 